\title{
Identification of risk factors for mortality in COVID-19 patients
}

\author{
Eun Young Kim \\ Division of Trauma and Surgical Critical Care, Department of Surgery, Seoul St. Mary's Hospital, College of Medicine, The Catholic University of Korea, Seoul, \\ Korea
}

Since the first case of coronavirus disease 2019 (COVID-19) was announced in China in January 2020, the disease has increased rapidly, becoming a pandemic, with 39,171,178 infected and 1,100,855 deaths worldwide as of October 2020. In Korea, 25,199 infections and 444 deaths have been reported since the first case in 2020 [1]. As the global pandemic persisted, problems such as limited medical resources, intensive care unit (ICU) equipment, and medical staff shortages gradually intensified. Accordingly, more efficient operation and securing of limited medical resources have become essential. In particular, if medical shortages are realized, it may be difficult to achieve timely hospitalization and adequate intensive care such as mechanical ventilation, especially for severe cases of COVID-19. If treatment is delayed, serious problems such as deteriorating health or unnecessary death may occur in patients with severe disease or for performance of time-sensitive elective operation, such as cancer or transplant surgery. Moreover, there may be gaps in the medical surveillance system of mild or asymptomatic infections, which increase the risk of infection and transmission to the community. Therefore, appropriate hospitalization and risk identification strategies for mortality or critical complications are needed. Although the overall mortality rate of COVID-19 is less than $3 \%[2,3]$ and most cases are mild, the clinical deterioration rate is fast and mortality increases rapidly in severe cases requiring ventilation support or ICU admission. Considering these characteristics of COVID-19, cases with risk of exacerbation in severity should be quickly identified and transferred to a medical institution that can preferentially provide intensive care. In mild cases, local quarantine centers or home quarantine should be considered in consideration of the local community and the risk of infection. Therefore, it is essential to determine the risk factors that can accurately predict the mortality and occurrence of severe complications of COVID-19 patients. Several large-scale studies recently published have reported on these factors. In the multicenter study of Guan et al. [4], old age, presence of comorbidity, and prominent laboratory abnormalities such as lymphopenia and leukopenia were characteristic features of severe COVID-19, and Goyal et al. [5] reported male, obesity, elevated liver function enzymes, and inflammatory markers as risk factors for mechanical ventilation in COVID-19 patients. In the current study, the authors report that elderly over the age of 60 , presence of diabetes or ischemic heart disease, ICU admission, neutrophil to lymphocyte rate $\geq 3.3$, and international normalized ratio $\geq 1.2$ are significant factors that increase mortality risk, consistent with existing reports.

However, as the authors mentioned, there could be bias or limitations in the analysis of effective factors due to the single-center, retrospective design of the study with small numbers

\section{Editorial}

Received: October 21, 2020

Accepted: October 26, 2020

Corresponding author

Eun Young Kim

Division of Trauma and Surgical

Critical Care, Department of Surgery,

Seoul St. Mary's Hospital, College of

Medicine, The Catholic University of

Korea, 222 Banpo-daero, Seocho-gu,

Seoul 06591, Korea

Tel: +82-2-2258-2876

Fax: +82-2-595-2822

E-mail: freesshs@naver.com

Copyright (@) 2020 The Korean Society of Critical Care Medicine

This is an Open Access article distributed under the terms of Creative Attributions Non-Commercial License (https:// creativecommons.org/li-censes/by-nc/4.0/) which permits unrestricted noncommercial use, distribution, and reproduction in any medium, provided the original work is properly cited. 
of patients. In addition, given the differences among countries in healthcare systems and in countermeasures and medical systems for asymptomatic patients or patients living at home, there is a limit to accepting the results of this study as a universal risk factor for all infected patients. Therefore, the results of large-scale research involving multiple nations and multicenters are necessary. In addition, relapse and reinfection have been reported even after viral negativity and represent a new risk of quarantine, efforts to identify predisposing factors also are needed.

Nevertheless, identification of factors related to COVID-19 mortality and progression to critical conditions can help to improve prognosis, especially in the present long-term pandemic with no effective vaccination. Also, such knowledge can help to efficiently provide limited medical resources to patients in need of emergency and intensive care, including non-COVID patients.

\section{CONFLICT OF INTEREST}

No potential conflict of interest relevant to this article was reported.

\section{ORCID}

Eun Young Kim https://orcid.org/0000-0003-4408-4165

\section{REFERENCES}

1. Central Disaster Management Headquarters of Korea. The overseas outbreak of coronavirus disease (COVID-2019) [Internet]. Sejong: Ministry of Health and Welfar; 2020 [cited 2020 Oct 26]. Available from: http://ncov.mohw.go.kr/index.jsp.

2. National Health Commission of the People's Republic of China. Diagnosis and treatment protocol for COVID-19 (trial version 8) etiological \& epidemiological characteristics [Internet]. Beijing: National Health Commission of the People's Republic of China; 2020 [cited 2020 Oct 26]. Available from: https://en.nhc.gov.cn/healthtips.html.

3. World Health Organization. Coronavirus disease (COVID-2019) situation reports [Internet]. Geneva: World Health Organization; 2020 [cited 2020 Oct 26]. Available from: https://www. who.int/emergencies/diseases/novel-coronavirus-2019/situation-reports/.

4. Guan WJ, Ni ZY, Hu Y, Liang WH, Ou CQ, He JX, et al. Clinical characteristics of coronavirus disease 2019 in China. N Engl J Med 2020;382:1708-20.

5. Goyal P, Choi JJ, Pinheiro LC, Schenck EJ, Chen R, Jabri A, et al. Clinical characteristics of Covid-19 in New York city. N Engl J Med 2020;382:2372-4. 